Revista de la red interuniversitaria de estudios sobre las literaturas rioplatenses contemporáneas en Francia

$11 \mid 2014$

De niños e infancias

\title{
Ay, niñez perpetua
}

\section{Pablo Katchadjian}

URL: http://journals.openedition.org/lirico/1831

DOI: $10.4000 /$ lirico.1831

ISSN: 2262-8339

Editor

Réseau interuniversitaire d'étude des littératures contemporaines du Río de la Plata

\section{Referencia electrónica}

Pablo Katchadjian, «Ay, niñez perpetua », Cuadernos LIRICO [En línea], 11 | 2014, Puesto en línea el 01 diciembre 2014, consultado el 12 mayo 2019. URL : http://journals.openedition.org/lirico/1831 ; DOI : 10.4000/lirico.1831

Este documento fue generado automáticamente el 12 mayo 2019.

\section{(c) $($ ) $(9)$}

Cuadernos LIRICO está distribuido bajo una Licencia Creative Commons Atribución-NoComercialSinDerivar 4.0 Internacional. 


\title{
Ay, niñez perpetua
}

\author{
Pablo Katchadjian
}

\section{NOTA DEL EDITOR}

Pablo Katchadjian (Buenos Aires, 1977). Publicó La libertad total (Bajo la luna, 2013), La cadena del desánimo (Blatt \& Ríos, 2012), Gracias (Blatt \& Ríos, 2011), Mucho trabajo (Spiral Jetty, 2011), Qué hacer (Bajo la luna, 2010), El Aleph engordado (IAP, 2009), El Martín Fierro ordenado alfabéticamente (IAP, 2007) y tres libros de poesía : el cam del alch (IAP, 2005), dp canta el alma (Vox, 2004) y, en colaboración con Marcelo Galindo y Santiago Pintabona, los albañiles (IAP, 2005).

\section{Ay, niñez perpetua}

1 Estamos, no sé bien con quiénes, en una plaza. Somos unas ocho personas y parece una tarde otoñal. De repente alguien dice: "Vienen los vampiros”. “¿Los vampiros? ¿Y qué hay que hacer?", pregunto yo. "Nada", me responden : "quedate quieto y no hagas nada". La gente que está conmigo se queda quieta, como suspendida, pero yo no puedo evitar acercarme a la chica que está al lado mío y agarrarla suavemente por la cintura, desde atrás, tocarle los hombros con delicadeza y darle unos besos muy suaves en el cuello y en la mejilla izquierda. Me doy cuenta, mientras lo hago, de que ella debe pensar que soy un vampiro, aunque no está asustada sino que, con los ojos cerrados, sonríe y parece disfrutar y saber que no soy un vampiro. Enseguida llegan los vampiros y se acercan a nosotros. Uno me agarra el brazo. “¿Cómo se hace ?”, le pregunto. "No, vos no hacés nada, yo te voy a morder acá", me responde mientras descubre mi hombro y me clava los colmillos ahí. De repente es como si estuviera en la cabeza del vampiro, como si sintiera en su lugar, y la sensación es increíblemente agradable. Ahí me despierta mi mamá y me dice que se hizo tarde, que nos quedamos todos dormidos. Desayunamos rápidamente y me lleva a la escuela. Tengo once años, y quizá por eso cuando, en el recreo, les cuento a 
mis amigos lo que soñé, ellos no saben qué decir: a algunos les da asco, pero otros parecen sentir el mismo tipo de excitación rara que sentí yo. "En el sueño yo era un adulto", les digo. “¿En serio?”, me pregunta Peter, realmente asombrado. "Sí”, le respondo. "Pero los vampiros no existen", me dice Rodrigo con cara de inteligente. " $i Y$ eso qué tiene que ver?", le respondo. "¡Eso no tiene nada que ver !", le grita Samuel. "Son muy tontos ustedes", dice Rodrigo, y se va. Samuel dice : "Es muy bobo este Rodrigo". Y Peter acota: “¡Con ese nombre!”. “QQué tiene el nombre?”, pregunta Casio. "Es un nombre tonto", dice Peter. "Sí, es cierto", dice Silas. "¿Y vas a volver a soñar esto ?", me pregunta Peter. "No sé", le digo. "Yo una vez soñé cinco noches seguidas lo mismo", dice Casio. “¿En serio?”, le pregunto. “Sí”, dice Casio. “¿Y qué era?”, le pregunta Silas. "Soñaba que escupía y me despertaba con toda la almohada escupida", dice Casio. Todos nos reímos con carcajadas excesivas. Alguno dice " ¡qué asco !", otro “ ¡no puede ser !" y otro “ja mí también me pasó !”. Y, mientras, sigilosamente, algo por un agujero se va, se va, se va, pasa, pasa, se evapora, se pierde... Es agua estancada en un rincón que va siendo absorbida por el cemento muy de a poco. "Ay, niñez perdida", dice Rodrigo, que vuelve comiéndose un alfajor. “¿Qué dijiste ?”, le preguntamos casi todos. Y él responde : "Nada, que siento que el agua estancada esa, que cada vez es menos, de alguna manera...”. Pero no puede terminar, porque le saltamos encima con bronca y le pegamos hasta que él logra levantarse y se escapa rengueando y con la ropa desarreglada. Tiene el alfajor aplastado en la cara. "¡Qué tarado!”, dice Peter. “increíble !”, dice Silas. "Pero con ese nombre no se puede esperar otra cosa". "Y... no", decimos todos, aunque no estamos convencidos: ¿qué tiene el nombre de malo? ¿Por qué el nombre es terrible en él y no en los otros Rodrigos? ¿Quién es realmente Rodrigo? De repente, los cinco, callados, estamos mirando el charco de agua. Más tarde, en la hora de gimnasia, escuchamos sin parar la risa de Rodrigo mientras habla con una chica de trece. La chica también se ríe mucho. Esa noche no podemos dormir y soñamos cosas que no entendemos. Al día siguiente, es Rodrigo quien interpreta nuestros sueños. Unos meses después, Rodrigo se muda de país con su familia. De ahí hasta fin de año no dejamos de hablar de él. Actualmente Rodrigo se dedica a las telecomunicaciones.

\section{Reunión familiar}

2 Juan estaba furioso, sus ojos llenos de lágrimas, se sentía defraudado. Se le acercó su madre y le dijo: “¿Por qué estás furioso, con tus ojos llenos de lágrimas, y te sentís defraudado ?”. Juan le respondió : “¡Porque soy así !”. Pero lo que pensaba, en realidad, era que su vida nunca volvería a ser la misma. Su madre le dijo : “¿Por qué pensás que tu vida nunca volverá a ser la misma?”. Y Juan le respondió : “¡Porque me siento mal !”. Pero en realidad lo que pensaba era que su madre estaba muy fea. Ella entonces le dijo: “¿Por qué pensás que estoy muy fea ?”. Juan le respondió: “Porque ese peinado te queda mal". Pero lo que en verdad pensaba era que los zapatos de su madre eran horribles. Entonces ella le dijo: “¿Por qué pensás que estos zapatos son horribles?”. Y Juan le respondió: "¡Porque es lo primero que se me ocurre!”. Y, mientras lo decía, a varias cuadras de allí un hombre peleaba con un perro. Entonces su madre le dijo : “¿Por qué el hombre pelea con el perro ?". Y Juan le dijo : “Porque el perro no entiende cuando se le habla bien !". Pero en verdad el hombre sentía que ese perro era lo mejor que le había pasado en la vida. Entonces la madre le dijo a Juan: “¿Por qué ese hombre siente que su perro es lo mejor que le pasó en la vida ?". Y Juan le respondió : “Porque nunca hubo un 
momento más feliz para él que éste que nosotros estamos viviendo ahora". Sin embargo, la mujer del hombre del perro, en ese mismo instante, estaba en su oficina y recordaba su casamiento, que había ocurrido veinte años atrás. Entonces la madre le dijo a Juan: “¿Pensás que el vestido de casamiento de la mujer era apropiado ?”. Y Juan le dijo : “Por supuesto !". Sin embargo, en ese mismo momento la mujer pensaba que su vestido había sido pobre, pero dadas las circunstancias la mejor opción. Juan le dijo entonces a la madre : "De ninguna manera era la mejor opción". Y la madre asintió mientras pensaba que su hijo estaba muy tonto. "No tengo nada de tonto", le dijo Juan. "No, tenés razón, pero de alguna manera lo que decís me recuerda algo que dijo un amigo muy tonto hace muchos años", le respondió la madre mientras pensaba en ese amigo, que ahora usaba peluca para cubrir su calvicie. “¿Y si se sacara la peluca ?”, preguntó Juan, y el hombre de la peluca, que en ese momento estaba en su oficina, se sacó la peluca y la tiró a la basura. "Así está mejor", dijo la madre mientras recordaba que el padre de Juan, de quien se había separado hacía ya diez años, solía usar un pulóver verde muy desagradable. "¡Pero ya no lo uso más !", dijo el padre. "Es cierto", dijeron Juan y la madre, "y además se te ve muy bien". "Gracias", dijo el padre, a la vez que pensaba en los zapatos de la madre de Juan. “¡Otra vez con mis zapatos!”, gritó la madre. “'Son muy lindos !”, dijo el padre, y Juan asintió.

\section{No existe}

3 “¿Te comerías a Adelfa ?”, me preguntó Filias una tarde mientras nos hamacábamos. "No, no me comería a ninguna persona", le contesté. Y hoy, casi veinte años después, mientras me adentro en el bosquecillo que descubrí ayer, pienso que quizá, con ayuda, podría hacerlo. "Sí, querido Filias, me comería a Adelfa", le respondo ahora, aunque él no puede oírme porque, en este momento, está estudiando en otro país. ¿Y este bosquecillo ? Es un bosquecillo que encontré paseando ayer. ¿Que dónde estoy? Estoy yo también, como Filias, lejos, a cientos de kilómetros de mi casa, en una cabaña solitaria. Vine a leer y a pensar, pero ayer, al toparme con el bosquecillo, me sentí perdido. Es que me hablaron los árboles, los insectos, los animalitos... Y lo primero que los animalitos me preguntaron fue : ¿Te comerías a alguno de nosotros ?”. Yo no respondí nada, sólo escuché lo que ellos me decían y, luego de veinte minutos, volví a mi cabaña, donde no pude comer ni dormir debido a la perturbación. Y ahora, hoy, cuando llegue al bosquecillo les voy a decir: "Sí, me comería a alguien y también a Adelfa". Y cuando me pregunten quién es Adelfa, les voy a contestar : "Adelfa era mi abuela". Cosa no del todo cierta, porque Adelfa era mi tía. Y si les hablo de Filias y me preguntan quién es Filias, les voy a contestar: "Filias es mi primo". Cosa tampoco del todo cierta, porque Filias es mi hermano. Les voy a decir que Filias está haciendo un doctorado en una universidad extranjera, algo menos falso que lo anterior, porque Filias está haciendo un post doctorado en una universidad extranjera. “¿Qué es un post doctorado ?", me va a preguntar una ardilla, y yo le voy a decir: "No es nada". Cosa totalmente falsa, pero sería para sacármela de encima, seguramente sin éxito. Aunque, si uno lo piensa, no sería desatinado esperar que las personas puedan aceptar una explicación visiblemente falsa y dejen de preguntar si notan que a uno lo incomoda cierto tema. ¿Haría una ardilla algo así ? Por qué no. Ya veremos. Pero ahora no encuentro el bosquecillo, y tengo que decir que no encontrarlo me desagrada y me preocupa. "Ay, bosquecillo", digo en voz alta, y siento el rumor del viento en los árboles, que, aunque parezca, no es una respuesta. Cuando ayer los árboles me 
hablaron, su voz era clara y varonil; las ardillas conversaban agudo, y las plantas siseando; los insectos murmuraban: las arañas chillaban y los escarabajos tenían voz ronca. "¡Ay, bosquecillo !", vuelvo a decir, y los árboles vuelven a rumorear, y yo entonces me pregunto: “Qué es esto de bosquecillo? ¿Qué es esa palabra?”. Me sorprende la pregunta y me sorprende mi primer pensamiento : un bosquecillo no puede ser nada. En todo caso debería ser un bosquecito, o al menos un pequeño bosque. Pero bosquecillo... Disculpen, amigos animales: hoy me voy a perder el coloquio. "Ay, si no fuera tan idiota...".

\section{Canción infantil soviética : Tren azul}

4 Lentamente los minutos se alejan flotando, y no espero volver a verlos. Quizá nos sentimos tristes porque nuestro pasado se va, pero todo lo mejor está por venir. Suavemente, suavemente, el largo camino se abre frente a nosotros y cruza el horizonte. Todos deberían creer y desear lo mejor, y nuestro tren azul avanza. Tal vez en algún momento herimos a alguien sin querer : el calendario va a pasar esa página por nosotros. Y apurémonos a buscar nuevas aventuras, digámosle al maquinista que acelere el tren. Suavemente, suavemente, el largo camino se abre frente a nosotros y cruza el horizonte. Todos deberían creer y desear lo mejor, y nuestro tren azul avanza. Nuestro tren azul avanza y se balancea : es un tren expreso y realmente está acelerando. ¿Por qué debería terminarse este día ? Me gustaría que durara un año entero. Suavemente, suavemente, el largo camino se abre frente a nosotros y cruza el horizonte. Todos deberían creer y desear lo mejor, y nuestro tren azul avanza. Si los lugares por lo que avanza a veces nos inquietan, no deberíamos preocuparnos. El futuro no está tan lejos, pero por suerte no demasiado cerca. No queremos que esto se termine, y si tenemos empeño no va a terminarse nunca. Suavemente, suavemente, el largo camino se abre frente a nosotros y cruza el horizonte. Todos deberían creer y desear lo mejor, y nuestro tren azul avanza. Cuando miro a mis acompañantes a veces desconfío. ¿Qué los trae junto a mí? ¿Qué esperan de este viaje? Pero estas preocupaciones son rápidamente disueltas por el sol o por la luna, que desde la ventana nos iluminan alternativamente las caras. Suavemente, suavemente, el largo camino se abre frente a nosotros y cruza el horizonte. Todos deberían creer y desear lo mejor, y nuestro tren azul avanza. Si no avanzara estaría descansando; si no fuera un descanso estaríamos en problemas. Pero, finalmente, ¿qué diferencia hay entre el descanso y el problema? Todo es parte de la vida, y todo lo que ella nos da es para que entendamos mejor nuestro destino. Suavemente, suavemente, el largo camino se abre frente a nosotros y cruza el horizonte. Todos deberían creer y desear lo mejor, y nuestro tren azul avanza. Algunos de los colores que vemos al pasar son estimulantes, pero otros parecen hechos para sacarnos las energías. ¿Qué es la energía, y dónde está? ¿Quién se va a animar a negarnos aquello por lo que luchamos? Nada llega sin esfuerzo, y el esfuerzo es el barniz que protege los tesoros entregados. Suavemente, suavemente, el largo camino se abre frente a nosotros y cruza el horizonte. Todos deberían creer y desear lo mejor, y nuestro tren azul avanza. Algunas veces creemos estar enamorados, pero esto sólo ocurre cuando no sabemos qué es el amor. Si de repente nos hiciéramos la pregunta, deberíamos tratar de olvidarla. No hay que pensar demasiado sobre lo que nos alegra: las ideas sólo sirven para poner el tren en marcha cuando se detiene. Suavemente, suavemente, el largo camino se abre frente a nosotros y cruza el horizonte. Todos deberían creer y desear lo mejor, y nuestro tren azul avanza. No es tan 
cuidadoso el que nos habla con melindres; tampoco es hostil el que nos grita y nos exige. Todos están dispuestos a ayudarnos si somos capaces de entregar cariño : beberán cuando les llenemos la copa, fumarán cuando prendamos la pipa. Suavemente, suavemente, el largo camino se abre frente a nosotros y cruza el horizonte. Todos deberían creer y desear lo mejor, y nuestro tren azul avanza. Si alguno de ustedes piensa que me equivoco, probablemente tenga razón. Prefiero equivocarme a andar temblando, y además las equivocaciones no existen en el cielo. Miramos cómo el sol se oculta tras la nube. ¿O es la nube la que oculta al sol de nosotros? ¿O nos esconde a nosotros de él? Suavemente, suavemente, el largo camino se abre frente a nosotros y cruza el horizonte. Todos deberían creer y desear lo mejor, y nuestro tren azul avanza. Hay una flor en un florero de vidrio ; si quiero ver el tallo no tengo más que mirar. Si el agua está muy turbia tendría que cambiarla, pero eso ¿es un problema? No, es una acción. No dejemos que un demonio travieso nos mueva los brazos, y si el demonio ya nos tiene, cortemos los hilos con firmeza y cantémosle al demonio : "Suavemente, suavemente, el largo camino se abre frente a nosotros y cruza el horizonte. Todos deberían creer y desear lo mejor, y nuestro tren azul avanza". 